Tohoku J. Exper. Med., 1961, 75, 263-26\%

\title{
Enzymatic Anomaly of Erythrocytes in Congenital Nonspherocytic Hemolytic Anemia
}

(The Second Report)

\author{
By
}

Keiya Tada

From the Department of Pediatrics, Faculty of Medicine, Tohoku University, Sendai; Director: Prof. Ts. Arakawa

(Received for publication, August 2, 1961)

In a previous paper, "1 the author reported an enzymatic anomaly of erythrocytes, consisting of a low content of reduced glutathione (GSH), an abnormality in the reduced glutathione stability test, and a low activity of glucose-6phosphate dehydrogenase (G6PD), in a pedigree of congenital nonspherocytic hemolytic anemia. Recently the same enzymatic anomaly of erythrocytes was demonstrated in the family of another pedigree. In this paper, the enzymological studies in both pedigrees were described.

Case I. A 40-day-old girl was admitted to our Hospital because of severe, prolonged jaundice from the 4 th day of life. The family history revealed that an elder brother and a maternal first cousin died of jaundice in early infancy

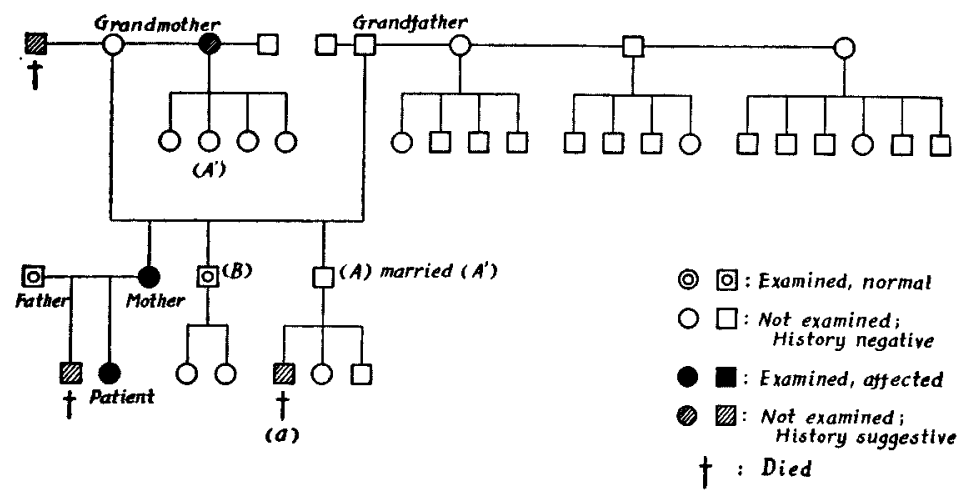

Fig. 1. Pedigree of case I

(cf. Fig. 1). There was no history of jaundice or anemia in the relatives of the father's side. The parents were not consanguineous but appeared to be healthy. 
An uneventful full-term pregnancy and spontaneous delivery were noted. Physical examination on admission showed a well-developed infant except remarkable jaundice and hepatosplenomegaly. The liver with smooth surface was palpable $4 \mathrm{~cm}$ below the right costal margin and the spleen was palpable $1.5 \mathrm{~cm}$ below the left costal margin. Otherwise, no abnormal findings were present.

Case II. A 14-year-old boy was admitted to our Hospital because of unusual hemolytic anemia. Jaundice and anemia occurred soon after birth and had ever continued with fluctuation of severity from time to time. The family history revealed a high incidence of anemia in the relatives of the mother's side but none in the father's side (cf. Fig. 2). The parents were not consanguineous

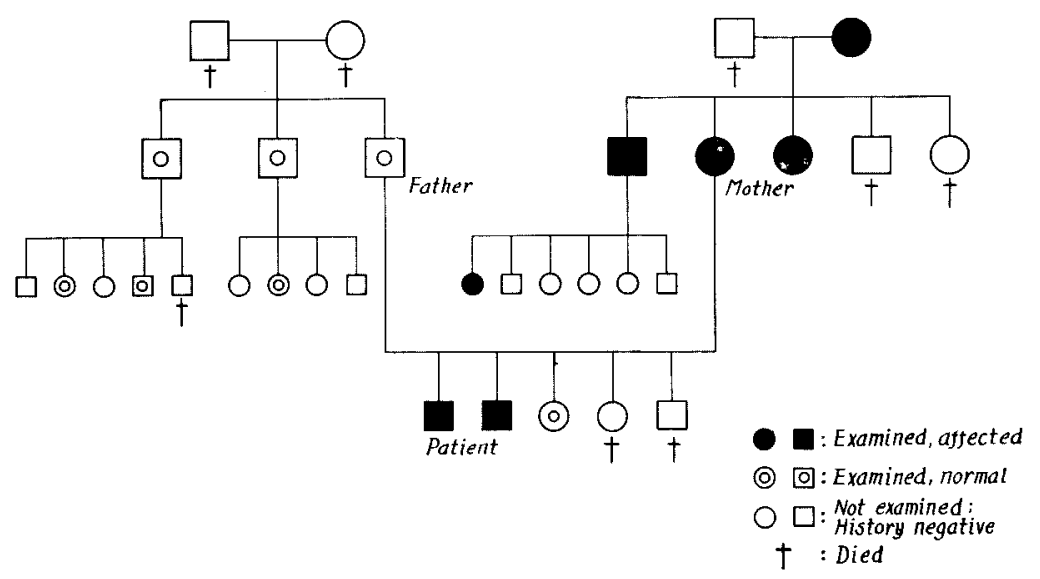

Fig. 2. Pedigree of case II

but appeared to be healthy. Physical examination on admission showed a moderately nourished boy with subicteric and pale skin. The liver was not palpable but the spleen was palpable $2 \mathrm{~cm}$ below the left costal margin. Otherwise, no abnormal findings were present.

Laboratory examinations: No blood-group incompatibility between the patient and the mother could be demonstrated in either case. The Coomb tests, both direct and indirect, and Wassermann's reaction were negative in both cases. Hematological examinations of both patients (cf. Table I) showed a mild anemia and reticulocytosis with the absence of spherocytes, of normoblasts or of any other morphologically abnormal erythrocytes. Elevations of icterus index and of serum bilirubin, especially of indirect fraction, were remarkable and the Hijmans van den Bergh reaction was negative for direct and markedly positive for indirect in both patients (cf. Table II). Excretion of urinary and fecal urobilinogen also was increased. The liver function tests were within normal 
TABLE I. Hematological Examinations.

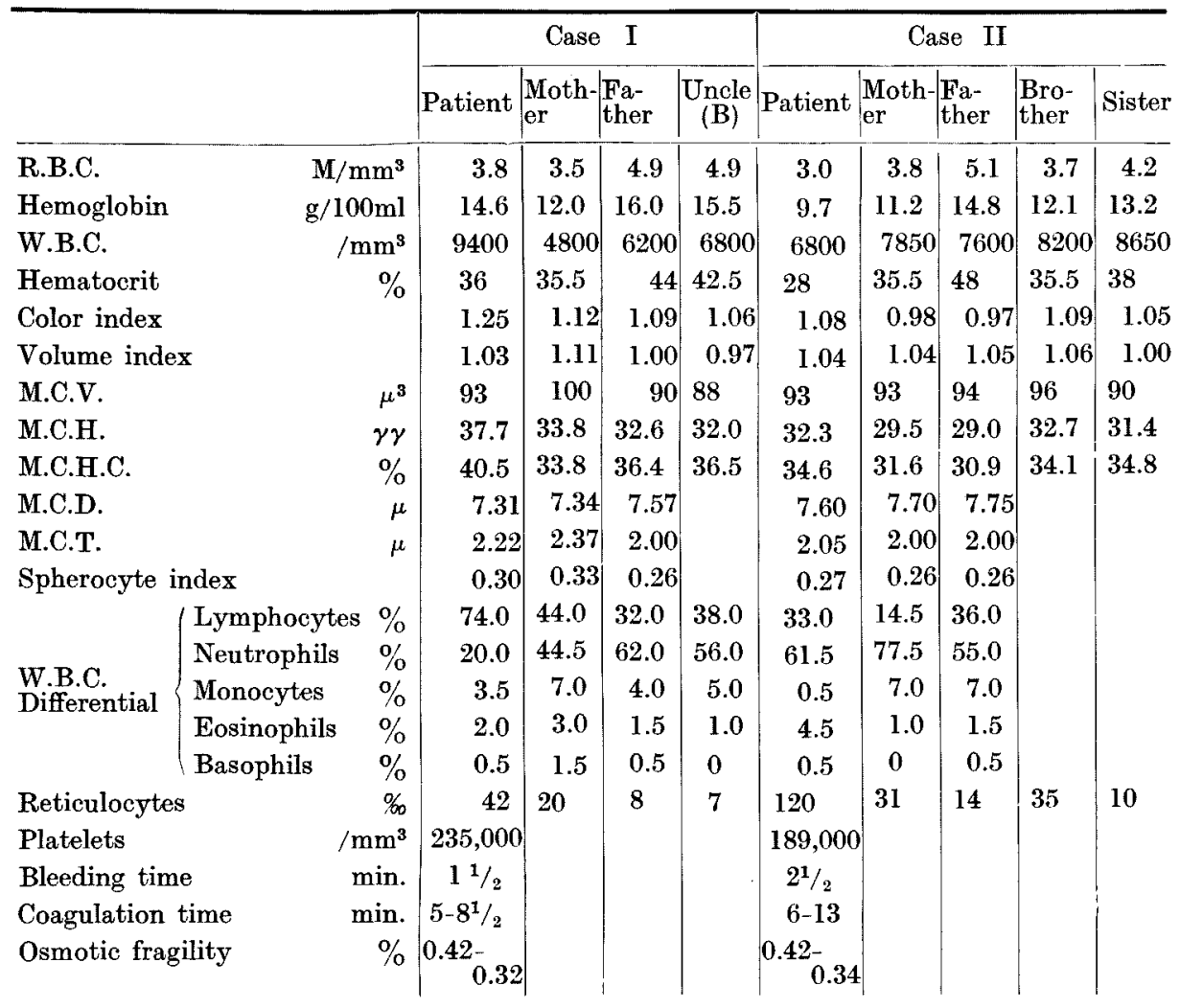

limits (cf. Table II). E.K.G. and X-ray examination revealed no evidence of abnormalities in both patients. An evidence of hemolytic anemia in a milder degree was disclosed by examinations in their mothers who seemed to be healthy in appearance (cf. Tables I and II). Basing upon the above-mentioned results, the diagnosis of congenital nonspherocytic hemolytic anemia was made for both cases.

GSH content in erythrocytes and the GSH stability test (cf. Table III) The determination of GSH content in erythrocytes and the GSH stability test were carried out as described in a previous paper of mine.1) The erythrocytes of both patients had a low level of GSH as compared with that of controls. As to the GSH stability test, GSH in erythrocytes from the patients showed a remarkable drop after incubation with acetylphenylhydrazine, while GSH in erythrocytes from controls remained almost unchanged after the incubation. The erythrocytes from the mothers showed a relatively low content of GSH as well as diminished stability of GSH in a milder degree. On the other hand, 
TABLE II. Biochemical Examinations.

\begin{tabular}{|c|c|c|c|c|c|c|c|c|c|c|}
\hline & \multicolumn{4}{|c|}{ Case I } & \multicolumn{5}{|c|}{ Case II } \\
\hline & & Patient & Moth- & $\begin{array}{l}\text { a- } \\
\text { her }\end{array}$ & $\mid \begin{array}{c}\text { Uncle } \\
\text { (B) }\end{array}$ & Patient & \begin{tabular}{|l|} 
Moth- \\
er
\end{tabular} & $\begin{array}{l}\mid \text { Fa- } \\
\text { ther }\end{array}$ & Bro- & Sister \\
\hline Serum & $\begin{array}{l}\text { Icterus index } \\
\text { Hijmans van } \begin{array}{l}\text { direct } \\
\text { den Bergh } \\
\text { indirect }\end{array} \\
\text { Bilirubin }\left\{\begin{array}{l}\text { total } \\
\text { mg/dl }\end{array}\right.\end{array}$ & $\begin{array}{r}94 \\
(-) \\
(H) \\
10.0 \\
7.9\end{array}$ & $\begin{array}{r}12.5 \\
(-) \\
(+) \\
1.0 \\
0.7\end{array}$ & \begin{tabular}{r|}
8.0 \\
$(-)$ \\
$(-)$ \\
0.6 \\
0.1
\end{tabular} & $\begin{array}{l}7.0 \\
(-) \\
(-) \\
0.5 \\
0.1\end{array}$ & $\begin{array}{r}23 \\
(-) \\
(+1) \\
3.7 \\
3.2\end{array}$ & \begin{tabular}{r|}
13.5 \\
$(-)$ \\
$(+)$ \\
1.2 \\
1.0
\end{tabular} & $\left|\begin{array}{r}6.0 \\
(-) \\
(-) \\
0.5 \\
0.2\end{array}\right|$ & $\begin{array}{r}16.0 \\
(-) \\
(+) \\
1.4 \\
1.1\end{array}$ & $\begin{array}{l}5.0 \\
(-) \\
(-) \\
0.4 \\
0.1\end{array}$ \\
\hline $\begin{array}{l}\text { Liver } \\
\text { function } \\
\text { tests }\end{array}$ & $\begin{array}{l}\text { Thymol turbidity } \\
\text { Takada's reaction } \\
\text { Cobalt reaction } \\
\text { B.P.S. 30 min. } \\
\text { Alkaline phos- } \\
\text { phatase B.U. }\end{array}$ & $\begin{array}{l}1.0 \\
(-) \\
\mathbf{R}_{3} \\
3.0 \\
5.0\end{array}$ & 0.8 & 1.3 & 1.8 & $\begin{array}{l}3.2 \\
(-) \\
\mathbf{R}_{6} \\
2.5 \\
4.6\end{array}$ & 1.2 & 1.5 & 1.3 & 2.0 \\
\hline Urine & $\begin{array}{l}\text { Urobilinogen } \\
\text { (Lepehne's method) } \\
\text { Bilirubin } \\
\text { Sugar } \\
\text { Protein } \\
\text { Urobilinogen/day }\end{array}$ & $\left|\begin{array}{c}16 \text { times } \\
(+) \\
(-) \\
(-) \\
(-) \\
100 \mathrm{mg}\end{array}\right|$ & $\begin{array}{l}( \pm) \\
(-) \\
(-) \\
(-)\end{array}$ & $\begin{array}{l}(-) \\
(-) \\
(-) \\
(-)\end{array}$ & $\begin{array}{l}(-) \\
(-) \\
(-) \\
(-)\end{array}$ & $\left|\begin{array}{c}32 \text { times } \\
(+) \\
(-) \\
(-) \\
(-) \\
>600 \mathrm{mg}\end{array}\right|$ & $\left|\begin{array}{c}2 \text { times } \\
(+) \\
(-) \\
(-) \\
(-)\end{array}\right|$ & $\left.\mid \begin{array}{l}(-) \\
(-) \\
(-) \\
(-)\end{array}\right]$ & $\left|\begin{array}{c}4 \text { times } \\
(+) \\
(-) \\
(-) \\
(-)\end{array}\right|$ & $\begin{array}{l}(-) \\
(-) \\
(-) \\
(-)\end{array}$ \\
\hline Feces & $\begin{array}{l}\text { Parasite } \\
\text { Occult blood }\end{array}$ & $\begin{array}{l}(-) \\
(-)\end{array}$ & & & & $\begin{array}{l}(-) \\
(-)\end{array}$ & & & & \\
\hline
\end{tabular}

the erythrocytes from the fathers showed normal values both in GSH content and in the GSH stability test.

G6PD activity in erythrocytes (cf. Fig. 3)

The activity of G6PD in erythrocytes was assayed as described in a previous paper" ${ }^{1 \prime}$ of mine. The erythrocytes from both patients showed a very low activity as compared with those from controls. The erythrocytes from the mothers showed a moderate degree of deficiency of G6PD activity, while those from the fathers showed normal activity.

Among those family members tested in each family, there was a definite correlationship between the severity of hemolytic anemia and metabolic abnormalities in erythrocytes-low activity of G6PD, low content of GSH and GSH instability. Further experiments are related in the DISCUSSION.

\section{DISCUSSION}

The metabolic anomaly of erythrocytes, consisting of a low content of GSH, GSH instability and a low activity of G6PD, was for the first time demonstrated by Beutler et al. ${ }^{2-7)}$ in drug-induced hemolytic anemia. The present author was able to demonstrate the same lesion in erythrocytes from two families of congenital nonspherocytic hemolytic anemia, although my own patients had hemolytic 
TABLE III. GSH Content in Erythrocytes and GSH Stability Test.

\begin{tabular}{|c|c|c|c|c|}
\hline & & $\begin{array}{c}\text { GSH } \\
(\mathrm{mg} / 100 \mathrm{cc} \text { RBC })\end{array}$ & $\begin{array}{l}\text { GSH (mg/lo0cc RBC) } \\
\text { after } 2 \text { hours of incu- } \\
\text { bation with APH* }\end{array}$ & $\begin{array}{l}\text { Rate of decrease of } \\
\text { GSH during incuba- } \\
\text { tion }\end{array}$ \\
\hline Control & $\begin{array}{l}\text { Adults } \\
\text { (5 cases) } \\
\text { Infants } \\
(5 \text { cases }) \\
1-2 \text { months of } \\
\text { age } \\
\text { Children } \\
(5 \text { cases }) \\
10-15 \text { years of } \\
\text { age }\end{array}$ & $\begin{array}{l}74.5 \pm 4.8 \\
88.3 \pm 6.1 \\
74.9 \pm 7.6\end{array}$ & $\begin{array}{l}69.0 \pm 4.6 \\
81.9 \pm 4.4 \\
68.1 \pm 5.4\end{array}$ & $\begin{array}{l}7.4 \% \pm 3.1 \\
7.0 \% \pm 4.0 \\
8.8 \% \pm 6.3\end{array}$ \\
\hline Case I & $\begin{array}{l}\text { Patient } \\
\text { Mother } \\
\text { Father } \\
\text { Uncle (B) }\end{array}$ & $\begin{array}{l}43.6 \\
59.5 \\
72.0 \\
67.5\end{array}$ & $\begin{array}{l}12.8 \\
40.8 \\
66.3 \\
62.5\end{array}$ & $\begin{array}{r}70.6 \% \\
31.5 \% \\
8.0 \% \\
7.5 \%\end{array}$ \\
\hline Case II & $\begin{array}{l}\text { Patient } \\
\text { Mother } \\
\text { Father } \\
\text { Brother } \\
\text { Sister }\end{array}$ & $\begin{array}{l}59.0 \\
68.5 \\
79.0 \\
67.5 \\
79.0\end{array}$ & $\begin{array}{l}28.5 \\
45.0 \\
73.0 \\
50.5 \\
70.5\end{array}$ & $\begin{array}{r}51.7 \% \\
34.3 \% \\
7.6 \% \\
2.25 \% \\
10.8 \%\end{array}$ \\
\hline
\end{tabular}

* Acetylphenylhydrazine

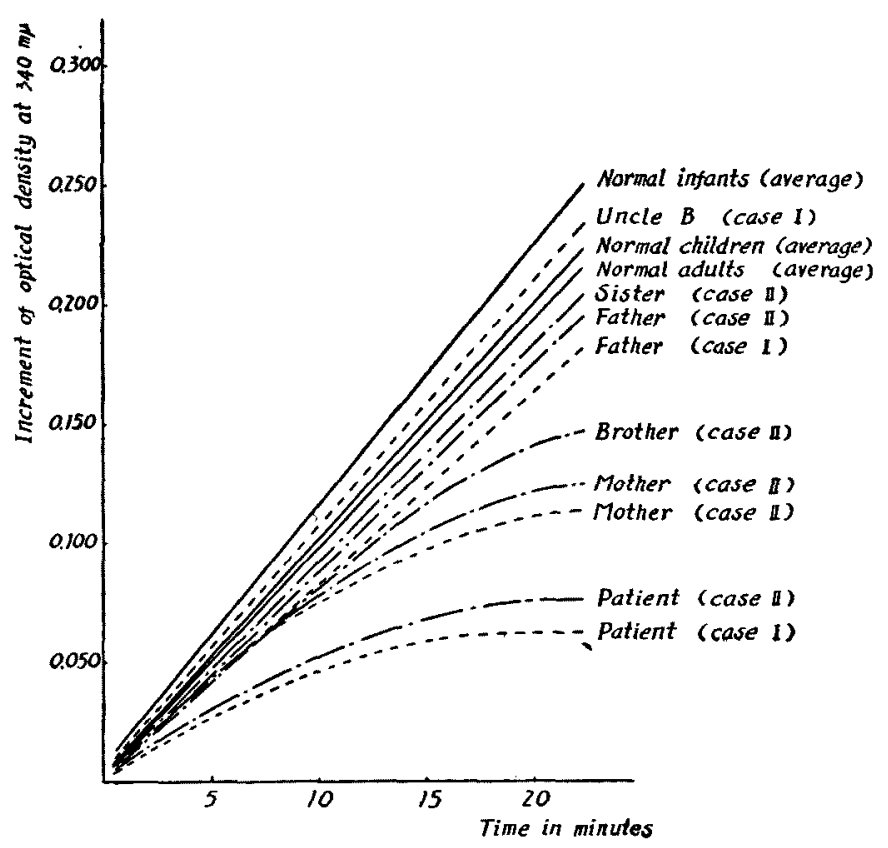

Fig. 3. G6PD activity in erythrocytes 
anemia soon after birth without exposure to any drug. Now Beutler's syndrome and that in my own cases-are they of the same clinical entity? The difference seems to lie in the inducing agent. In the former the agent was certain drugs and in my own cases such an apparent agent was lacking. Can this be indeed an essential difference between the two? Now I tried to solve this problem by a

TABLE IV. Influence by Administration of Domian and Phenacetin to the Patient of Case II.

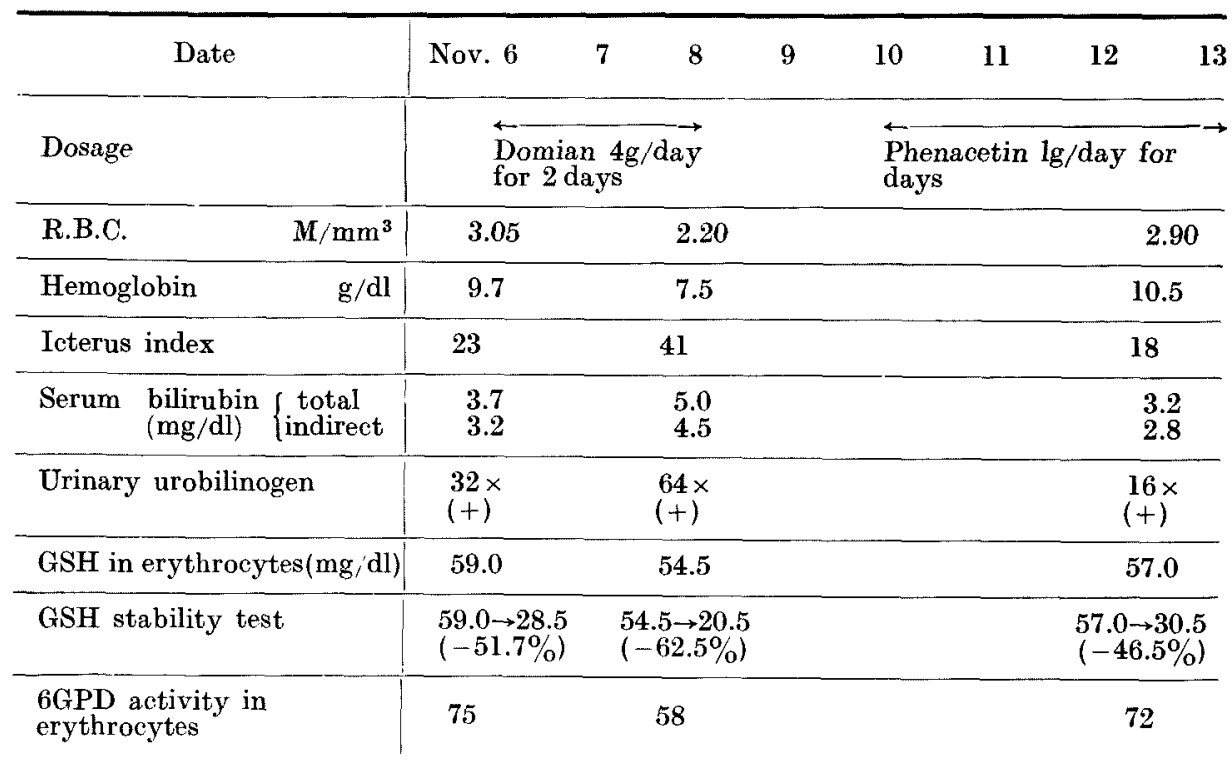

clinical experiment (ef. Table IV). Domian (6-sulfanilamido-2,4-dimethylpyrimidine $^{3)}$ ) and phenacetin ${ }^{3)}$ are each reported to be as an inducing agent in drug-induced hemolytic anemia. To Case II of my own patients I gave Domian, $4.0 \mathrm{~g}$ per day in three doses for two consecutive days. The results were a decrease of erythroctye counts from $3.05 \times 10^{6}$ to $2.20 \times 10^{6}$ per $\mathrm{mm}^{3}$ and of hemoglobin from 9.7 to $7.5 \mathrm{~g} / \mathrm{dl}$, accompanied with distinct signs of aggravated hemolysis such as an elevation of icterus index, of serum bilirubin, especially of indirect fraction, and of urinary excretion of urobilinogen. At the same time, G6PD activity, GSH content and GSH stability in erythrocytes showed a marked decrease. One week later these aggravated signs of hemolysis and metabolic disturbances in erythrocytes returned to the level before administration of Domian, in spite of administration of phenacetin $1.0 \mathrm{~g}$ per day in three divided doses for four consecutive days. This indicates that phenacetin in this dosage had no effect on hemolysis and that the spontaneous recovery of aggravated anemia due to Domian administration took place merely by discontinuence of the drug Domian. I tried also the control experiments. The same dosage of Domian 
and phenacetin was administered to healthy children, but no significant change of hemolytic signs, GSH content and G6PD activity in erythrocytes occurred. These experimental results seem to suggest that the difference between the congenital nonspherocytic hemolytic anemia and the drug-induced hemolytic anemia is not necessarily essential but rather quantitative, so that the pathogenesis for hemolysis is highly probably the same in both disorders and the difference may be due to severity of gene-penetrance of abnormal trait.

It remains, however, uncertain whether or not so-called "congenital nonspherocytic hemolytic anemia" is an entity from viewpoint of pathogenesis, since a case of "congenital nonspherocytic hemolytic anemia" is at present diagnosed by excluding other well-known kinds of hemolytic anemia such as congenital spherocytosis, erythroblastosis fetalis or the hemoglobinopathies. It remains to be solved whether all cases of congenital nonspherocytic anemia have the above-mentioned metabolic disturbances in erythrocytes. It may be worthy of notice in a veiw of genetics that the two families reported here were of the same area in Yamagata Prefecture.

\section{SUMMARY}

Two families of congenital nonspherocytic hemolytic anemia were reported. A metabolic abnormality in the erythrocytes from the patients was demonstrated, consisting of a low content of GSH, an abnormality in the GSH stability test and a low activity of G6PD. These abnormalities were also found in the erythrocytes from the mothers in a milder degree, while there was no abnormalities in the erythrocytes from the fathers. An aggravation of hemolysis and metabolic disturbances mentioned above was observed following administration of Domian (6-sulfanilamido-2,4-dimethylpyrimidine) to the patient.

It was also argued by way of experiment that the difference between the so-called congenital nonspherocytic hemolytic anemia and drug-induced hemolytic anemia is not essential, but only quantitative, so that both disorders belong highly probably to the same entity of enzymopathy from the viewpoint of pathogenesis of hemolysis.

\section{References}

1) Tada, K. \& Mizuno, H., Tohoku J. Exp. Med., 1961, 74, 18.

2) Beutler, E. et al., J. Lab. \& Clin. Med., 1955, 45, 286.

3) Dern, R. J. et al., J. Lab. \& Clin. Med., 1955, 45, 30.

4) Szeinberg, A. et al., Blood, 1957, 12, 603.

5) Beutler, E. et al., J. Lab. \& Clin. Med., 1957, 49, 84.

6) Alving, A. S. et al., Ann. Int. Med., 1958, 49, 240.

7) Carson, P. E. et al., Science, 1956, 124, 484.

8) Houston, I. B. \& Barlow, A. M., Lancet, 1959, ii, 1062. 